Article

\title{
Rural Homelessness in Western Canada: Lessons Learned from Diverse Communities
}

\author{
Jeannette Waegemakers Schiff ${ }^{1}$, Rebecca Schiff ${ }^{2, *}$ and Alina Turner ${ }^{3}$ \\ ${ }^{1}$ Faculty of Social Work, University of Calgary, Calgary, T2N 1N4, Canada; E-Mail: schiff@ucalgary.ca \\ 2 Department of Health Sciences, Lakehead University, Thunder Bay, L3V 0B9, Canada; E-Mail: rschiff@mun.ca \\ 3 Turner Research and Strategy Inc., Calgary, T2X 2P5, Canada; E-Mail: turneralina@gmail.com \\ * Corresponding author
}

Submitted: 31 March 2016 | Accepted: 5 August 2016 | Published: 20 October 2016

\begin{abstract}
Until recently, there was little acknowledgement that homelessness existed in rural areas in Canada. Limited research and scarce data are available to understand the scope and dynamics of rural homelessness in Canada. As suggested in our previous work, there is a need for rural homelessness research to examine themes from a provincial perspective. The aim of this research was to contribute to expanding the knowledge base on the nature of rural homelessness at a provincial level in the Canadian province of Alberta. In order to understand the dynamics of homelessness in rural Alberta, we conducted interviews with service providers and other key stakeholders across Alberta. We examined homelessness dynamics and responses to rural homelessness in 20 rural communities across the province. Across all of the communities in the study, homelessness was reported however, the magnitude of the issue and its dynamics were distinct depending on the local contexts. We also identified several themes which serve as descriptors of rural homelessness issues. We note a number of recommendations emerging from this data which are aimed at building on the experiences, capacities, and strengths of rural communities.
\end{abstract}

\section{Keywords}

Canada; disaster management; domestic violence; homelessness; Housing First; immigrant; indigenous persons; rural; seniors; youth

Issue

This article is part of the issue "Homelessness and Social Inclusion", edited by Isobel Anderson (University of Stirling, UK), Maša Filipovič Hrast (University of Ljubljana, Slovenia) and Joe Finnerty (University College Cork, Ireland).

(C) 2016 by the authors; licensee Cogitatio (Lisbon, Portugal). This article is licensed under a Creative Commons Attribution 4.0 International License (CC BY).

\section{Introduction}

With a few exceptions, most research and interventions that focus on homelessness have concentrated on those living in urban areas. The visibility of urban homelessness, the ability to readily estimate their numbers, differences in profile from singles to families, children and youth to seniors, has made it possible to describe population characteristics and begin to determine ways of addressing need. The same cannot be said of the rural experience.

Anderson and $\operatorname{Sim}(2000,2011)$ note the significance of geographic location to social exclusion in housing. While there is a body of work from other countries such as the UK (see especially Cloke, Marsden, \& Mooney, 2006; Cloke \& Milbourne, 2012) and the United States (United States Government Accountability Office, 2010) which has more specifically focused on rural housing and social exclusion, there is little research available to understand the scope and dynamics of rural homelessness in Canada (Waegemakers Schiff, Schiff, Turner, \& Bernard, 2015). The aim of this research was to contribute to expanding the knowledge base on the nature of homelessness in rural Canadian communities. We begin with a review of the state of knowledge on rural homelessness in Canada. As Waegemakers Schiff et al. (2015) suggest, there is a need for rural homelessness 
research to capture common emerging themes from a provincial rather than community-by-community perspective. As such, this study also focuses beginning to address this need through an provincial examination of homelessness dynamics and responses to rural homelessness across 20 diverse rural communities in Alberta Canada. Through this process, our research uncovered a few significant trends with regards to the nature of rural homelessness in Alberta. In particular, we identified three themes which serve as descriptors of rural homelessness issues and are considered in the context of Canadian and international literature on rural homelessness. These themes focused on: Significant sub-populations; economic dynamics and; rural housing market dynamics. We also identified two other unique issues which are mostly unrecognised in the literature on homelessness and might be important considerations in understanding rural homelessness dynamics.

\section{Background: Rural Homelessness in Canada}

Until recently, there was little acknowledgement that homelessness existed in rural areas in Canada (Waegemakers Schiff et al., 2016). Understanding of rural homelessness is minimal compared to that focussed on urban populations, and assessment of needs within the nonurban population is often overlooked. Rural homelessness was unacknowledged in this country, until reports from diverse rural areas of Canada began to emerge in the last decade which shed light on the unique context of the issue (Christensen, 2011; Robertson \& White, 2007; Roy, Hurtubise, \& Rozier, 2003; Standing Senate Committee on Agriculture and Forestry, 2008). The combination of vast, sparsely inhabited spaces, a harsh climate, and minimal to non-existent social services in remote areas, provides the setting and unique challenges for those who are without adequate housing in rural Canada. Recent reports reveal considerable concerns over dwellings that provided inadequate shelter from the elements, others being unfit for human habitation, and people doubled up and living in extremely overcrowded situations (Christensen, 2012).

A combination of counts and estimates of homeless persons throughout Canada report that every night, at least 30,000 Canadians experience homelessness. Among them, almost 3,000 'sleep rough' indicating that they sleep in cars, parks or on the street and are considered unsheltered. Another 14,400 stay in emergency shelters, which are usually temporary and provide overnight sleeping facilities but often no day-time accommodation (Gaetz, Donaldson, Ruichter, \& Gulliver, 2013). Longer term stay is attributed to the 7,350 who stay in domestic violence shelters, although these facilities often have a 30 - or 60-day maximum length of stay. A final group includes more than 4,460 who are provisionally accommodated in hospitals, prisons or halfway houses who have no permanent residence to return to upon discharge from the facility (Gaetz, Donaldson, Ruichter, \&
Gulliver, 2013). The foregoing reflects urban homelessness. There are no accurate reports of how many people are homeless absolutely or relatively, in rural Canada.

With a few exceptions, most research and intervention has concentrated on individuals and families living in urban areas; consequently, homelessness has most often been framed as an urban phenomenon. In cities and towns, homeless individuals seek a range of support services, including food, overnight shelter and financial help at organizations established to address these needs. These activities make the urban homeless a visible population in many respects. This visibility, the ability to more readily estimate their numbers, and differences in profile (singles families, youth and seniors, aboriginal, immigrant and refugee), has made it possible to describe population characteristics and begin to determine ways of addressing their described needs in Canadian cities (Peressini, McDonald, \& Hulchanski, 1995).

In contrast, rural locations often do not have specific services for homeless people and consequently there are few places available for identification of those who may be in housing distress and consequently for data collection necessary for accurate counts. As a result, the extent of homelessness in different parts of rural Canada is simply unknown. Because rural homelessness is difficult to measure with any accuracy, measures of rural poverty and core housing need are often taken as proxy indicators. As such, they suggest that the rate of rural housing instability is similar to that in urban areas (Employment and Social Development Canada, 2011; United States Interagency Council on Homelessness, 2015). However, researchers in the United States (Fitchen, 1992; Lawrence, 1995) note that rural housing insecurity may be as ubiquitous as it is in urban settings, and homeless rates may be even higher than in urban areas when those living in substandard or unfit housing are included. Houses which would be routinely condemned in urban areas, fall outside of the view of local officials in rural areas and remain inhabited despite their unsafe condition (Robertson, Harris, Noftsinger, \& Fischer, 2007).

While rural homelessness has received some attention in Australia (Grigg, Judd, Ryan, \& Komiti, 2005), the United States (Fitchen, 1992; Lawrence, 1995; Robertson et al., 2007) and England (Cloke, Milbourne, \& Widdowfield, 2000, 2001, 2003), what little is known about rural homelessness in Canada is confined to small body of academic literature and a group of local reports which generally focus on discrete communities and sub-regions in disparate parts of the country. Some have a general overview of rural homelessness in a given region and others are focused on discrete populations such as Aboriginal people (Belanger \& Weasel Head, 2013; Kauppi, Pallard, McGregor, \& Seyler, 2015), northern remote areas (Christensen, 2012), and those with a serious mental illness (Forchuk et al., 2010). The lack of consolidated information across the country hinders a clear understanding of the specificity and complexity of Canadian rural homelessness and thus hampers efforts to tailor programs and 
initiatives aimed at alleviating homelessness in rural environments (Waegemakers Schiff et al., 2016).

A recent review of the literature on rural homelessness in Canada (Waegemakers Schiff et al., 2016) suggests that there is a need for research to capture common emerging themes from a provincial rather than community-by-community perspective. They suggest that, due to the vastness of Canada and its immense regional variation, a provincial perspective is a more manageable stepping-stone to a detailed national understanding. In keeping with this recommendation, this research focused on a province-wide investigation of homelessness in rural Alberta. We examined homelessness dynamics and responses to rural homelessness in 20 rural communities across the province. In this process, we were able to provide a preliminary assessment of nature of this issue and local responses to rural homelessness across these communities.

\section{Alberta Context}

Alberta is primarily a rural province, with large expanses of sparsely settled areas, two major cities (pop. $1,250,000$ and 812,000 ), and a few larger urban clusters. Although the size of France, Alberta is primarily a rural province, with large expanses of sparsely settled areas, multiple small communities (pop. less than 2,500 persons) which are surrounded by vast swatches of range land, farm land, arboreal forests as well as mountainous areas. Resultantly, we utilised a data gathering approach (see Methodology) that would represent all of these variations. The province is divided, for economic analysis, into fourteen regions, with two major urban regions (Capital and Calgary which were omitted from the study). The remaining 12 regions are mainly rural in na-
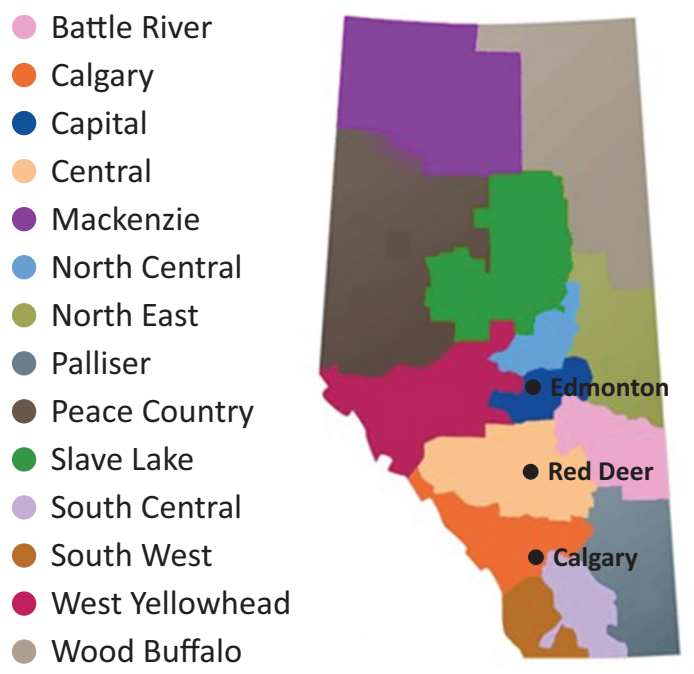

Figure 1. Alberta economic regions (2015). Source: Government of Alberta. Available at http://www. albertacanada.com/business/statistics/regional-econo mic-indicators.aspx ture, although six host cities of 35,000 to 130,000 . Rural regions of the province also vary as dominated by either agricultural, energy sector (oil and gas) or recreational/tourist characteristics (see Figure 1).

\section{Methodology}

In order to understand the dynamics of homelessness in rural Alberta, we conducted interviews with service providers and other key stakeholders across Alberta. The participants for this study came from two sources; local representatives who had familiarity with the social services and housing demands in their communities as well as key government officials and stakeholders of larger province-wide organizations. For this study, we focused on Alberta's economic development regions (Figure 1) and targeted their rural settlements (Table 1). Using this selection, we then narrowed the targeted communities according to population size, densities, agricultural, energy sector (oil and gas) and recreational/tourist characteristics. Within these regions, 51 separate agencies were contacted and 20 communities participated in the study. The study was limited to rural communities with populations under 25,000 to align methods to a concurrent national study (Waegemakers Schiff \& Turner, 2014). Study communities had an average of 7,000 residents. The 20 communities involved directly with the study were: Athabasca; Beaver County (Ryley); Brooks; Camrose; Chestermere; Claresholm; Coaldale; Cochrane; Didsbury; Fairview; Fort Mackay; High Level; Jasper; Lac La Biche; Redwater; Pincher Creek; Rocky Mountain House; Slave Lake; St. Paul; Wetaskiwin.

Within these communities we identified and contacted key individuals in government and the local social services coordinating organizations which are allied with

Table 1. Alberta economic development regions and associated study communities.

\begin{tabular}{ll}
\hline Economic Region & Community \\
\hline Battle River & Camrose \\
Calgary & Chestermere; Cochrane \\
Capital & Beaver County; Wetaskiwin \\
Central & Didsbury \\
Mackenzie & High Level \\
North Central & Athabasca; Redwater \\
North East & Lac La Biche; St. Paul \\
Palliser & Brooks \\
Peace County & Fairview \\
Slave Lake & Slave Lake \\
South Central & Claresholm; Coaldale \\
South West & Pincher Creek \\
West Yellowhead & Jasper; Rocky Mountain House \\
Wood Buffalo & Fort Mackay \\
\hline
\end{tabular}


Family and Community Support Services office across the entire province and requested their participation. For all identified stakeholders and local representatives, phone calls and emails were followed with recruitment packages that contained both the interview guide, ethics approval and informed consent documents.

Between February to April 2014 we conducted interviews with key informants in 20 communities across all of these economic regions and 6 stakeholders at the provincial services level. The narrow time-frame minimized any potential impact of political and economic forces on the regions. Data were collected using a template for surveying rural communities that had been previously developed and used in a national survey of rural homelessness (Waegemakers Schiff \& Turner, 2014), with the addition of a few modifying questions salient to the Western Canadian context. Homelessness was defined according to the Canadian Definition of Homelessness (Canadian Observatory on Homelessness, 2012). The study included both 'hidden' and visible forms of homelessness, such as rough sleeping, couch surfing, doubled up and sheltered populations. A graduate research assistant who was experienced in interviewing arranged and conducted most of the community interviews which were primarily telephone-based.

\section{Data Analysis}

For each community we created a profile based on key indicators (population size, percent of persons with low income, size of the Aboriginal population) and descriptors arising from the interviews with respect to housing conditions, migration dynamics, homelessness trends, and action on homelessness in the community. We supplemented these community descriptors with a data base that contained 19 key community variables including location, access to major centre, macroeconomic trends (community type as defined by Bruce et al. (2005), proximity to First Nations reserve(s), households in core housing need as identified in the national housing study (Canada Mortgage and Housing Corporation [CMHC], http://www.cmhc-schl.gc.ca/en/hoficlincl/ homain/stda/data/data_013.cfm), homeless population estimates and trends, the local homelessness response including emergency shelters, rental subsidies, homeless action plan, system coordination across social services organizations, and awareness of and implementation of a housing first approach. These were quantified so that we could use a cluster analysis, based on the community profiles compiled from key indicators and descriptors, to aid in in thematic analysis through characterization of groups of communities according to common parameters.

\section{Findings}

Across all of the study communities in the study, homelessness was reported and this impression was confirmed by the provincial stakeholders. However, the mag- nitude of the issue and its dynamics were distinct depending on the idiosyncrasies of local contexts. Nevertheless, on the whole, most community representatives included in the study pointed to the existence of homelessness as something that has 'always been there' to a certain extent. Interviewees also noted that rural homelessness differs from the urban because of its 'hiddenness'. The rural homeless population was reported to be quite mobile, constantly moving from place to place. While interviewees noted issues of outmigration from urban centres to rural areas, and migration between rural communities, there was no identification of migration of the urban poor to rural areas as noted in Belgium by Meert and Bourgeois (2005).

Rural homelessness was described as a 'hidden phenomena,' characterized by families and individuals doubling up and couch surfing, or living in makeshift housing (unsafe housing, trailers, camping out, etc.). Doubling up and couch surfing were the most often-cited manifestations of rural homelessness. A small amount of visible homelessness was reported in the form of transient people loitering in town centres, rough sleeping and people sheltered in shelters in the few towns where these exist. On a per capita basis, some study communities reported quantifiable homelessness prevalence rates. For example, an interviewee from High Level estimated the community to have a homeless population of about 30 people; for a town with a population of 3,610 , this would result in a homelessness prevalence rate of $0.8 \%$. Comparatively, Calgary, which is known to have one of the highest urban homelessness rates nationally, reports an estimated $0.307 \%$ prevalence rate (Calgary Homeless Foundation, 2013). Smaller study communities that did not have shelters also reported in some instances that transportation was provided, usually through bus tickets, to locations where shelters exists. This practice also minimizes the extent of the homeless population as many of those transported out cannot easily return.

Our research also uncovered a few significant trends with regards to the nature of rural homelessness, program approaches, and policy responses in Alberta. In particular, we identified three themes which serve as descriptors of rural homelessness issues. These themes focused on: Significant sub-populations; economic dynamics and; rural housing market dynamics. We also identified two other unique issues which are mostly unrecognised in the literature on homelessness and might be important considerations in understanding rural homelessness dynamics. One of these issues was of a geographic nature, addressing the issue of parks and recreational areas. The other was of a temporal nature, relating to the impact of disaster situations on homelessness dynamics and service systems.

\section{Notable Sub-Populations}

Interviewees identified six distinct sub-populations of people experiencing homelessness in rural areas of the 
province. These included: victims of domestic violence; youth; newcomers; indigenous persons, chronic substance (alcohol) abusers, and chronically homeless people. Notably, interviewees did not mention those with mental health problems, despite the fact that they are a significant part of urban homelessness (Hwang, Stergiopoulos, O’Campo, \& Gozdzik, 2012).

\subsection{Victims of Domestic Violence}

Domestic violence was cited as a key driver to housing instability and homelessness, not only as a direct factor in pathways into homelessness, but also for its long term repercussions. This is not surprising as Family issues and domestic violence are frequently cited as factors that precipitate rural homelessness (Glass, 2002; Kauppi et al., 2012; Lee, Budgell, \& Skinner, 2007; Peters \& Robillard, 2009). Community and provincial stakeholders noted the impacts of domestic violence for women, youth, children and seniors, leading to loss of housing and various forms of hidden homelessness. In rural Alberta contexts, the available options for those escaping abuse are much more limited than in urban centres; an issue that is reflected in some of the other Canadian literature (Callaghan \& Turnbull, 1999; Yukon Anti-Poverty Coalition, 2011). Women fleeing violence have to leave their communities to escape their abusers, which also takes them out of their network of social supports.

A network of women's shelters is in place across $33 \mathrm{Al}$ berta communities. About 45\% (15) of these are located outside Alberta's main seven cities. The proximity and availability of women's shelters plays a key role in migration to access services as women and children have to leave their community to seek safety and support in localities with such services. Many sought supports in other rural communities with women's shelters. This is especially true for Indigenous people, as the Alberta Council of Women's Shelters reported that as many as $70 \%$ of domestic shelter users across the province are Indigenous women. This also reflects reports from other areas (Kauppi, 2012; Schmidt, Hrenchuk, Bopp, \& Poole, 2015). Resultantly, in recent years, an increasing complexity of presenting issues for such centres is also reported.

Indigenous women face the additional challenges engendered by systematic racism and sexism upon arrival at their destination. Interviewees reported that landlords are often cautious to rent to women fleeing violence, particularly when they are Indigenous and have children with them for fear of damages to their units or 'partying' and over-crowding from relatives and friends doubling up. These reports are similar to those from Nunavut (Schmidt et al., 2015) and northern Ontario (Kauppi, Pallard, \& Shaikh, 2013). One encouraging initiative suggests that solutions tailored to this group are emerging in rural Alberta. Landlords in Camrose are working with Indigenous women fleeing violence, making rental units available to them. Support workers advocate on behalf of the women and support housing stabil- ity. As a result, landlords are now 'lining up' to be part of the initiative as the women proved to be 'ideal tenants': stable, caring for the property, and paying rent on time.

\subsection{Youth}

Youth were another group that emerged as a notable sub-population of the rural homeless. Study communities reported homeless youth to be even less visible on the street, and most likely to couch surf and double up. Youth homelessness was often un-recognized from an official perspective, though interviewees remarked it to be a notable emerging issue. These reports are similar to those that come from many rural areas such as Nova Scotia (Karabanow, Naylor, \& Aube, 2014), Ontario (Martin, 2013), and Manitoba (E. Peters \& Craig, 2014).

Youth were reported to be homeless most often as result of abuse in the home, which led to notable movement and transience as they sought a safe place to live outside their familial home. The gendered experience of domestic and sexual violence impacts youth further. Sexual and gender identity, identified as a key driver in youth homelessness (Gaetz, 2014) adds yet another dimension in rural contexts. These dynamics often led to significant movement into urban centres. Youth serving agencies in Edmonton, for example, anecdotally report as many as $40 \%$ of youth they serve come from rural communities. The impetus for migration of rural homeless youth has become an important area for further study as reflected in the work from Nova Scotia (Karabanow et al., 2014) and Ontario (Martin, 2013), but need to expand to develop programmatic and policy solutions.

One youth shelter was reported in the rural Alberta case study communities (Camrose). As in urban contexts, the service response to rural youth homelessness is entwined with child intervention services and education, particularly given the high rates of abuse reported. For most youth, the lack of access to treatment for counseling, mental health and addictions locally was yet another service gap and is a problem in many rural areas (Kauppi et al., 2015; Forchuk et al., 2010). Here, ongoing challenges of service coordination are noted to limit the range and comprehensiveness of responses to the issue. There is a need for service coordination to ensure developmentally appropriate supports and housing options for homeless youth in rural Alberta.

\subsection{Newcomers}

There is currently little to no discussion in the Canadian literature of homelessness among immigrants or refugees in rural areas. One report provides a description of homelessness among a diverse group of participants from several ethno-cultural communities in Windsor/Essex County, Ontario (Anucha, 2006). While it did not specifically address rurality as a dynamic in their experiences, the report notes that newcomers' homelessness in the area is precipitated by housing unaffordabil- 
ity. Through interviews conducted in this Alberta study, economic immigrants, refugees, refugee claimants and Temporary Foreign Workers emerged as a notable subpopulation experiencing hidden homelessness in some study communities. Where homelessness was reported among this group, it was most often described as a result of low income leading to doubling and over-crowding, or living in poor quality housing. Foreign workers accounted for a large proportion of those living in substandard living situations in certain regions. Many of these individuals are living together in groups in accommodations not suitable for many people. In certain areas, doubling up was reported to be a common trend due to the accommodations provided by employers.

For immigrant women experiencing domestic violence, the added element of rurality exacerbated their isolation and ability to access supports. For some, the prospect of leaving abusers to move to a larger urban centre when they have limited knowledge about Canadian social support and justice systems and competency in English leaves this group particularly vulnerable. When the spouse is also the woman's sponsor for immigration purposes, the situation is particularly more tenuous from a legal perspective as well (Walsh, Hanley, Ives, \& Hordyk, 2015).

\subsection{Indigenous Persons}

Several local and regional reports from across Canada have noted over-representation of Indigenous people in the homeless population (Kauppi et al., 2009; Hallstrom et al., 2013; Stewart \& Ramage, 2011) although the extent to which this applies in rural settings is unknown. Some rural literature has examined the context and process of migration and mobility between reserves and urban areas (Belanger, Weasel Head, \& Owasago, 2012; Christensen, 2011; Peters \& Robillard, 2009), though not specifically of the problems and dilemmas of their rural homeless experience. The majority of communities included in this study were located near Indigenous communities. In communities with relatively large Indigenous populations and/or proximity to reserves, the makeup of the homeless population consistently demonstrated an over-representation of Indigenous people. In areas where a high number of Indigenous communities and reserves exist near the town, there the majority of homeless people are reported to be Indigenous. In areas where no Indigenous over-representation was reported in the homeless population, limited proximity to Indigenous communities was also noted. There were however exceptions to this trend, as in the case of Fairview where Indigenous women made up as many as $75 \%$ of domestic violence shelter users despite no Indigenous communities being in close proximity.

In some areas, Indigenous people are deterred from using town services and encouraged to 'find their way down the highway' to larger cities; a trend which might be attributed to racist sentiments within smaller com- munities. The issue of racism as a confounding factor for rural homelessness among Indigenous people is also reported by Waegemakers Schiff et al. (2015). Many interviewees, who also noted their familiarity with local residents, reported that homeless Indigenous individuals were often the children of parents who survived the residential school system, and faced complex mental health and addictions issues, domestic violence and traumatic experiences, as well as Fetal Alcohol Spectrum Disorder (FASD), which is often undiagnosed, especially in adults.

Some literature and reports on homelessness among Indigenous people in Canada have focussed on migration between reserves and urban centres (Belanger \& Weasel Head, 2013; Christensen, 2012; Carle \& BelangerDion, 2003; Kauppi et al., 2009; Peters \& Robillard, 2009). Interviewees reported frequent migration from Indigenous communities. They also described migration as motivated by a number of factors, including poor housing conditions on-reserve, lack of employment and education opportunities, as well as the need to access services (medical, judiciary, counseling, etc.). Several researchers studying migration patterns have reported similar motivations (Belanger \& Weasel Head, 2013; Christensen, 2012; Peters \& Robillard, 2009). Lack of safety, abuse, and violence were also reported by interviewees to be main drivers out of Indigenous communities. This is a particularly salient theme for Indigenous women and children fleeing violence on-reserve who seek support outside their home communities.

It is important to distinguish the contexts in which Indigenous rural homelessness plays out. On-reserve homelessness has distinct dynamics that should be noted. As this particular study was not intended to study on-reserve homelessness, we strongly urge that future research specifically examine this issue. In the interim we briefly describe the dynamics reported in one rural Indigenous town that is on a reserve.

\subsection{Chronically Homeless Persons}

Several reports from across Canada have noted the existence of chronic homelessness in rural communities, although at rates lower than those found in urban settings (Waegemakers Schiff et al., 2015). People experiencing chronic homelessness were reported as a smaller component of the homeless populations across the study communities and were characterized by complex mental health, addiction, and FASD issues. Those suffering from these disabilities were regarded as relatively small group, numbering less than ten in a typical community. This group was consistently facing housing loss due to these challenges, as subsidized housing and support services are limited in rural areas. The lack of supports available to manage underlying issues leads to further housing instability. For those who struggle with addictions or mental illness in rural Canada, lack of treatment and support services are reported as scarce and there is little (or none, depending on the location) supportive housing 
(Callahan \& Turnbull, 1999; Forchuk et al., 2010; Glass, 2002; Grodzinski et al., 2011; Lee et al., 2007; Nunavut Housing Corporation, 2013; Smith \& Fuller, 2007; Stewart \& Ramage, 2011).

Some special populations present specific dynamics influencing their homelessness. Among those with living with mental illness and addictions, there are chronically homeless populations in rural Alberta communities which have become well known to the small pools of landlords. People so identified are often placed on a 'no-rent list'. Particularly during economic growth periods, this group is described as most often 'squeezed out' of existing rental stock by incoming migrant workers. Some of the communities included in the study had a local women's shelter, however, none had emergency homeless shelters available to all adults or to families, to accommodate those in need of basic shelter services. As a result, rough sleeping was commonly reported, along with individuals and families living in makeshift shelters, trailers and tents.

Rough sleeping was reported across Alberta; particularly during warmer months. A small number of homeless people can be found in ditches, backyards, and parks or forested areas. This corresponds to other reports of the various ways the absolutely homeless cope in rural areas (Glass, 2002; Lee et al., 2007; Peters \& Robillard, 2009). Notably, a significant proportion of chronically homeless and rough sleepers were reported to be Indigenous people, particularly in areas with proximity to First Nations or other Indigenous communities, which is also reported in other areas (Belanger \& Weasel Head, 2013; Kauppi et al., 2015; Peters \& Craig, 2014).

\section{Economic Dynamics}

Interviewees who reported homelessness to be a minor issue in their community were scarce. Most noted that homelessness was not only a major challenge to the social infrastructure of their locality, but even noted its prevalence and intensity to be increasing in recent years. This impact on communities is a dynamic that is mentioned (Young \& Moses, 2013) but has not been well explored in the literature. Across the 20 study communities, the reported homelessness trends appeared to be closely tied to macro-economic shifts in the global economy impacting Alberta; particularly as related to the oil and gas industry. While some sites are intimately engaged in oil and gas, others were indirectly impacted by the ebbs and flows in prosperity characteristics of the industry. These communities act as service centres, or stop-points between resource-extraction sites and larger urban centres. This echoes what is also reported to drive housing affordability in the western Artic (Young and Moses, 2013). Not surprisingly, northern Alberta areas reported a much more intimate link with the oil and gas industry, which was attributed to be a main driver in their homelessness population. The ties particular communities have with resource extraction, especially in north- ern regions or on corridors between urban centres and these sites, have a marked impact on housing markets and homelessness dynamics.

There are a number of reasons behind the reported strained housing markets, which must be contextualized in relation to the larger economic contexts impacting the locality. For example, some centres were experiencing rapid growth brought on by regional economic development, often tied to the oil and gas industry. The influx of new workers created increased competition for scarce housing, driving prices well beyond affordability for those of modest or low income means. A provincial stakeholder reported strained vacancy rates due to the pressure of migration related to oil and gas industry in the region. The oil and gas industry placed significant strain by also recruiting landlords directly to house their workforce. Companies rent out available units at top dollar for their workers, leaving a depleted stock for both secondary industry workers earning significantly less and the community's lower income populations.

Home ownership is also caught in this cycle as housing investment speculation leads to rapid increases in house prices, which squeeze out middle and lower income families. In turn, the pressure on an already limited rental stock increases as migrant workers and local lower income renters compete for available units, driving up costs. As an interviewee from Rocky Mountain House noted, 'things get worse, when things are good'referring to the fact that a booming economy creates stress on households. The impact of this housing crunch not only affects lower income, vulnerable groups, but also key workers who are unable to afford to live in such communities. These key workers include those in the social service, mental health, and addictions sectors among others; the shortage of such critical services providers hampers the service infrastructure in such centres. Unlike the larger urban centres where such issues are related to lack of social and support services (Kauppi et al., 2015), rural communities are much more sensitive to these economic swings and have fewer resources to mitigate the changing demands for these services (Kauppi et al., 2013).

Both provincial and local interviewees related homelessness to these dynamics. Notably, they reported that in general, local homeless populations resided in these study communities regardless of the ups and downs of the oil and gas industry. However, an emerging homeless population was identified as attracted by an economic boom. As unskilled migrants, often struggling with alcohol or drug issues, they brought an additional layer of complexity in psychosocial issues to the local homeless population in resource-dependent communities.

\section{Rural Housing Market Dynamics}

The housing markets in rural Alberta play a key role in homelessness dynamics. Purpose-built rental housing is very limited and the rate of development is significantly 
lower than that of larger urban centres. Most stock exists in the form of single family housing, spread out across a larger surface area than what is often seen in cities. While some study communities reported available housing to exist on the outskirts of town, the lack of public transportation limits lower income groups from accessing it.

The housing stock traditionally available to lower income groups, particularly those with complex mental health and addiction issues, is reported to take the form of rental units on the top floors of older commercial buildings in the town centre (usually on the main road going through the town). While a valuable and limited resource for those with limited incomes, these buildings are reported to be aging to the extent that many are on the slate for demolition. Other forms of housing include hotels and motels, which are rented for longer periods by oil and gas workers in some communities. However, low vacancy rates and high prices limit their accessibility for lower income families and individuals.

Another dynamic that plays out in farming communities involved in this study involves the longer process of corporatization that has pushed people into increasingly smaller areas available for cultivation. Over time, some of these families become squeezed out of available land, leading to over-crowding and living in poor quality housing. As result of these economic and housing market dynamics, low vacancy rates were reported in 13 of the 20 case study communities. Ten of these communities specifically noted rents were also on the rise locally, which is consistent with reported trends across Alberta (CMHC, 2013).

\section{Unique Regional Issues}

Two unique issues emerged in this research which are related to specific regional circumstances or events. The first issues identified was the impact of recreational areas on rural homelessness. Another issue which emerged was related to the impact and ability to respond to disasters and the impact on housing stability in rural areas.

\subsection{Recreational Areas}

An issue that has not been considered in the literature is the impact of recreational areas on homelessness dynamics. Alberta is home to several significant recreational areas which are fueled by both local use and a large tourist base. The recent rise in prosperity for many Albertans has also spawned an increase in secondary and recreational homes in rural areas near both summer and winter destinations. While there is a robust literature on locational impact of recreational (second home) ownership in Canada, and Alberta specifically (Bohlin, 1975; Halseth, 1998; McNicol \& Glorioso, 2014), there has not been specific or detailed consideration of the impact of these trends on homelessness dynamics. Notable are larger communities that are located in or near national parks such as Banff, Jasper and Canmore. Other smaller communities are also affected including those located near provincial parks and recreation areas, such as Sylvan Lake, Pigeon Lake, and towns in the Crowsnest Pass. Those located in national parks boundaries have unique constraints that are distinct from those communities located near but outside of park boundaries. National parks have severe restrictions on additional residential building construction which restricts housing availability, especially for those with lower incomes. Service industry workers and their families are most often impacted by these dynamics. While we recognize that the economic factors that influence homelessness are analogous to those created by energy sector development in other areas, the influences in recreational and tourist areas have unique aspects that require a separate examination.

\subsection{Disaster Homelessness}

In addition to other important aspects of rural housing and homelessness, we identified a need to address the significant challenges created by natural disasters. Interviews revealed that natural disasters hold the potential not only to contribute to acute homelessness but also significantly impact existing homeless people and services in affected areas. Two events that were recent in the context of the study were identified by participants: the June 2013 flooding which ravaged the city of Calgary and parts of southern Alberta and significantly impacted several First Nations (Environment and Climate Change Canada, 2014) and the 2011 fires in the town of Slave Lake that destroyed most of the infrastructure and $30 \%$ of all homes in the town (CBC News, 2011). The more recent 2016 fire that ravaged the town of Fort McMurray had significant impact on that municipality's infrastructure and housing (The Globe and Mail, 2016); the impact on homeless persons was also reported by some media outlets (McDermott, 2016). Despite the significance of these events, there is little in the peer-reviewed literature which considers their impact on homelessness dynamics.

The June floods of 2013 severely impacted the Stoney and Siksika First Nations and further exacerbated already hidden homelessness and dire housing conditions in Morley, Eden Valley, and nearby Rocky Mountain House. Promised emergency housing did not substantially materialize in these communities and many of those forced from their homes were living in motels in Calgary, Canmore and nearby areas for extended periods. Some families were doubled or tripled up with up to 19 individuals attempting to live in a three-bedroom dwelling. In other instances, family sub-units rotated their place of residence among several houses occupied by relatives, a version of couch surfing that involves entire families. These events continue to exacerbate an already problematic housing and homeless problem on these reserves and continues several years after the disaster. 
The experience of Slave Lake in the wake of the 2011 fires provide further learnings about the unique circumstances resulting from natural disasters. The housing situation faced by Slave Lake as a result of a massive fire led to more than 700 people were left homeless. Rebuilding has been a four-year plan and is now essentially complete. But in that time span, many lived in interim housing secured from the province, some on site and others in distant communities. This created unique set of circumstances whereby a large portion of the population could be considered homeless. At the same time, a strong economy fueled by the energy sector kept the local economy healthy and ensured rapid return of the local population. Most often, families were couch surfing and doubling up. Notably, there remained a reported 'base' homeless population that preceded the fire consisting of longer term homeless, who were struggling with mental health and addictions issues. Within the context of the disaster, homelessness-related supports and the needs of this group were reported to take a 'backseat' given the extent of the housing problem facing the general population.

The Slave Lake fire and June 2013 floods examples highlight the unique circumstances natural disasters can create in rural communities. As there is presently no work that explores this issue, a detailed consideration of the impacts of disasters on homelessness should be pursued to examine longer term effects of disasters on rural communities and consider impacts in future planning and emergency preparedness work. Because of the pervasive and specific housing challenges of indigenous people a specific consideration the uneven impacts of disasters on homelessness among Indigenous people, off and on-reserve should be undertaken.

\section{Conclusions and Recommendations}

The aim of this research was to respond to a need for rural homelessness research in Canada to examine issues from broader, provincial perspectives rather than community-by-community case study approach. As such, this study focused on an examination of homelessness dynamics and responses to rural homelessness in 20 rural communities, spanning the wide range of landscape geographies and economic regions in the province of Alberta.

In this study we became acutely aware of the ways in which international research on rural homelessness has similarities and differences, depending on geographical and political context. In comparison to the UK, where local authorities keep a closer count of those in housing need and research has been more precise (Cloke \& Milbourne, 2012), and the US where housing assistance by way of rental subsidies and social programs extends a bit further into small towns (United States Government Accountability Office, 2010), the rural areas of Canada are vast, under-served, under-populated and have few resources. Moreover, the concept of rurality in a densely populated country such as the UK generally concerns it- self with localities within ready access to urban areas and facilities, which significantly impacts the ways in which the needs of rural homeless people can be addressed. The vast stretches of Canadian and north western US states create additional challenges in location of homeless people, accessing and delivering services. One commonality which stretches across all of these geographies is the limited attention devoted to understanding the size of this population, the multiple aspects of, challenges and needs of the rural poor who are often on the edge of housing loss.

We identified a few significant trends with regards to the nature of rural homelessness in Alberta; some of which supports existing findings in other Canadian contexts and some of which add a new perspective to existing literature on rural homelessness in Canada. In particular, we identified a few issues which are mostly unrecognised in the literature on homelessness and might be important considerations in understanding rural homelessness dynamics. This includes the impact of economic dynamics and rural housing market dynamics on rural homelessness, the impact of recreational areas on rural homelessness, and the impact of natural disasters on homelessness populations and support systems in rural areas. We also note the importance of further exploration into homelessness related to the experiences of immigrants and refugees in rural areas; indigenous persons who choose to stay in rural areas, and chronically homeless people.

A number of recommendations emerging from this data are aimed at building on the experiences, capacities, and strengths of rural communities. A first and crucial step is the development of regional and systematic approaches as part of an intentional response to rural homelessness (Nichols \& Doberstein, 2016). This would include coordinating resources and developing systemic regional strategies as well as the tailoring of strategies to groups of communities with similar challenges in service delivery. Similar to larger efforts in urban areas, such approaches should include a comprehensive housing and service infrastructure plan to address housing instability in smaller centers as part of broader regional responses Kauppi, Pallard, Lemieux, and Matukala Nkosi, 2012; Schiff \& Brunger, 2015). The plans should also encourage exploration of innovative alternatives to shelter, which leverage local resources, and innovative adaptations of 'housing first' approaches in rural communities. There should also be consideration given to the integration of homelessness in future emergency preparedness initiatives to address 'disaster homelessness'.

We also note the need to identify strategies for enumerating rural homelessness. While the 2016 homeless Point-in-Time Count (initiated by the Government of Canada through the Homeless Partnering Strategy) will provide more accurate numbers on homelessness in key Canadian larger communities, rural communities do not have formalized data collection approaches with respect to homelessness to track the level of need for hous- 
ing. Most respondents provided anecdotal estimates, but were unable to point to data collection and analysis processes. This was reported to be a key hurdle to making the case for investment in responses locally and to understanding the needs of the population. Without a comprehensive needs assessment to determine the magnitude of the issue locally, and the needs of the population, service providers and advocates were hampered significantly.

Regional and systematic approaches must respond to the needs of priority sub-populations: Indigenous persons, victims of domestic violence, youth, seniors and immigrant newcomers. Indigenous people on- and off-reserve require targeted approaches to overcoming complex jurisdictional barriers to services and supports (Christensen, 2011; Peters \& Craig, 2014). Victims of domestic violence in many rural communities need alignment with housing and homelessness responses. Targeted responses to youth, seniors, and newcomers' housing stress and homelessness in rural communities also need to be developed.

There is a need to increase awareness of, and leadership for, rural housing and homelessness which will champion solutions at all levels of governance. Locally, rural communities of practice can be supported through targeted networking and capacity building activities in the areas of 'housing first' implementation, performance management, system planning, and research.

As many other authors cited in this article have noted, there has been scarcity of information about rural specific elements, although the recent spate of activity is beginning to address this gap. Emerging research priorities for a research agenda on rural homelessness should include: developing baseline information on rural homelessness; service infrastructure analysis to assess available resources and gaps systematically; probing macroeconomic impacts which affect homelessness dynamics in rural communities; increasing understandings of rural Indigenous homelessness, on and off-reserve and the role of migration; enhancing knowledge about rough sleeping and chronic homelessness in rural contexts; identifying potential policy responses and funding allocation models that meet the needs of rural residents and; tailoring housing first interventions in rural contexts, particularly to address the needs of priority sub-populations. Planning and implementation responses would be enhanced through the development of a combination of a research network to facilitate knowledge mobilization and a Canadian research agenda on rural homelessness.

\section{Acknowledgments}

The researchers would like to thank the Alberta Interagency Council on Homelessness, Ministry of Human Services and Alberta Centre for Child, Family and Community Research, who fully funded this study. We would like to thank the community representatives and provincial stakeholders who participated in this effort for their con- tributions and willingness to share their expertise and experience. A special thanks to Adrian de Zwart, MSW, for his research assistance support with this project.

\section{Conflict of Interest}

The authors have no conflict of interest to declare for this manuscript.

\section{References}

Anucha, U. (2007). Exits and Returns: An Exploratory Longitudinal Study of Homeless People in Windsor, Essex County. Canada Mortgage and Housing Corporation.

Anderson, I., \& Sim, D. (Eds.). (2000). Housing and social exclusion: Context and challenges. Coventry: Chartered Institute of Housing and Housing Studies Association.

Anderson, I., \& Sim, D. (Eds.). (2011). Housing and inequality. Coventry: Chartered Institute of Housing and Housing Studies Association.

Belanger, Y. D., Weasel Head, G., \& Owasago, U. (2012). Assessing urban Aboriginal housing and homelessness in Canada. Retrieved from http:// www.homelesshub.ca/ResourceFilesFinal_Belanger/ _Housing_and_Homeless_-_6_May_2012.pdf

Belanger, Y. D., Weasel Head, G. (2013). Urban Aboriginal homelessness and migration in Southern Alberta. Final report prepared for the Alberta Homelessness Research Consortium (AHRC). Edmonton, Alberta.

Bohlin, K. M. (1975). The spatial and economic impact of recreational expenditures and sales in the Pigeon Lake area of Alberta (Master's thesis). University of Alberta, Edmonton.

Bruce, D., Essex, S., Gilg, A., Yarwood, R., Smithers, J., \& Wilson, R. (2005). The geography of housing needs of low income persons in rural Canada. In S. Essex (Ed.), Rural change and sustainability: Agriculture, the environment and communities (pp. 265280). Cambridge, MA: CABI Publishing.

Calgary Homeless Foundation. (2013). Migration's impact on homelessness in Calgary. Retrieved from http://www.calgaryhomeless.com/wp-content/up/ uploads/Backgrounder_Migration.pdf

Callahan, M., \& Turnbull, I. (1999). Muskoka, Ontario: Understanding homelessness in Muskoka. Retrieved from http://homelesshub.ca/resource/muskokaontario-understanding-homelessness-muskoka

Canada Mortgage and Housing Corporation. (2013). Rental market report: Alberta highlights. Retrieved from http://www.cmhc-schl.gc.ca/odpub/esub/64483/ 64483_2013_B02.pdf?fr=1394817906330

Canadian Observatory on Homelessness. (2012). Canadian definition of homelessness. Homeless Hub. Retrieved from www.homelesshub.ca/homeless definition/

Carle, P., \& Belanger-Dion, L. (2003). Rapport de recherche sur la population itinérante et sans domi- 
cile fixe des Laurentides. Mont-Tremblant, Québec.

CBC News. (2011). Fire destroys $40 \%$ of Slave Lake: High winds, low humidity challenge firefighting efforts. Retrieved from http://www.cbc.ca/news/ canada/edmonton/fire-destroys-40-of-slave-lake1.981352

Christensen, J. B. (2011). Homeless in a homeland: Housing (in)security and homelessness in Inuvik and Yellowknife, Northwest Territories, Canada. Montréal: McGill University.

Christensen, J. (2012). 'They want a different life': Rural northern settlement dynamics and pathways to homelessness in Yellowknife and Inuvik, Northwest Territories. The Canadian Geographer/Le Géographe canadien, 56(4), 419-438.

Cloke, P., Milbourne, P., \& Widdowfield, R. (2000). The hidden and emerging spaces of rural homelessness. Environment and Planning A, 32(1), 77-90.

Cloke, P., Milbourne, P., \& Widdowfield, R. (2001). The geographies of homelessness in rural England. Regional Studies, 35(1), 23-27.

Cloke, P., Milbourne, P., \& Widdowfield, R. (2003). The complex mobilities of homeless people in rural England. Geoforum, 34(1), 21-35.

Cloke, P., \& Milbourne, P. (2012). International perspectives on rural homelessness. New York: Routledge.

Cloke, P., Marsden, T., \& Mooney, P. (2006). Handbook of rural studies. London: Sage.

Employment and Social Development Canada. (2011). August 2011: Rural and remote homelessness. Ottawa: Government of Canada. Retrieved from http:// www.esdc.gc.ca/eng/communities/homelessness/ publications_bulletins/august_2011.shtml

Environment and Climate Change Canada. (2014). Alberta's flood of floods in Canada's top ten weather stories for 2013. Retrieved from https:// www.ec.gc.ca/meteo-weather/default.asp?lang=En $\& n=5 B A 5 E A F C-1 \&$ offset $=2 \&$ toc $=$ hide

Fitchen, J. M. (1992). On the edge of homelessness: Rural poverty and housing insecurity. Rural Sociology, 57(2), 173-193.

Forchuk, C., Montgomery, P., Berman, H., Ward-Griffin, C., Csiernik, R., Gorlick, C., . . Riesterer, P. (2010). Gaining ground, losing ground: The paradoxes of rural homelessness. Canadian Journal of Nursing Research, 42(2), 138-152. Retrieved from http:// www.ingentaconnect.com/content/mcgill/cjnr/2010/ 00000042/00000002/art00013

Gaetz, S., Donaldson, J., Richter, T., \& Gulliver, T. (2013). The state of homelessnness in Canada. Retrieved from: http://homelesshub.ca/resource/statehomelessness-canada-2013

Gaetz, S. (2014). Coming of age: Reimagining the response to youth homelessness in Canada. Toronto: The Canadian Homelessness Research Network Press.

Glass, A. (2002). Faces of homelessness in a rural area: Housing issues and homelessness in the West
Kootenay Boundary region. Retrieved from http:// homeless.samhsa.gov/ResourceFiles/Faces_of_Home lessness_in_a_Rura I_Area-_Housing_Issues.pdf

Grigg, M., Judd, F., Ryan, L., \& Komiti, A. (2005). Identifying marginal housing for people with a mental illness living in rural and regional areas. Australian and New Zealand Journal of Psychiatry, 39(11-12), 995-1000. Retrieved from http://www.blackwell-synergy.com/ doi/abs/10.1111/j.1440-1614.2005.01703.x

Grodzinski, E., Londerville, J., Sutherns, R., \& Bentham, C. (2011). Rural homelessness study. Report prepared for the County of Wellington. Retrieved from http:// www.wellington.ca/en/socialservices/resources/well ingtoncountyruralhomelessnessstudy.pdf

Hallstrom, K., Coates, W., Mindel, K., Richter, S., \& Finseth, N. (2013). Open door needs assessment report. Retrieved from http://www.camroseopendoor.com/ uploads/1/8/5/7/18576650/open_door_needs_as sessment_report.pdf

Halseth, G. (1998). Cottage country in transition: A social geography of change and contention in the ruralrecreational countryside. Montréal: McGill-Queen's Press.

Hwang, S. W., Stergiopoulos, V., O'Campo, P., \& Gozdzik, A. (2012). Ending homelessness among people with mental illness: The At Home/Chez Soi randomized trial of a Housing First intervention in Toronto. BMC Public Health, 12(1), 787. doi:10.1186/1471-2458-12787

Karabanow, J., Naylor, T., \& Aube, C. (2014). From Place to Space: Exploring Youth Migration and Homelessness in Rural Nova Scotia. Journal of Rural \& Community Development, 9(2), 112-127.

Kauppi, C., Gasparini, J., Henri Pallard, L., Garg, R., Montgomery, P., Webster, S., .. ., \& Secretariat, H. P. (2009). Migratory and transient homelessness in Northern Ontario: A study of the pathways to becoming homeless in Sudbury and its related impacts. Sudbury, Ontario, Canada: Social Planning Council of Sudbury.

Kauppi, C., Pallard, D. H., Lemieux, S., \& Matukala Nkosi, T. (2012). Homelessness in Timmins. January 2011 Final report. Sudbury, Ontario, Canada: Poverty, Homelessness and Migration.

Kauppi, C., Pallard, H., \& Shaikh, A. (2013). Migration and homelessness: Exploring attachment to place amongst francophone, Anglophone and Indigenous people in Northeastern Ontario. Spaces \& Flows: An International Journal of Urban \& Extra Urban Studies, 3(1). 97-107.

Kauppi, C., Pallard, H., McGregor, D., \& Seyler, K. (2015). Homelessness and housing in a Northeastern Ontario, Canada, First Nation: A community-based project. OIDA International Journal of Sustainable Development, 8(4), 51-66.

Lawrence, M. (1995). Rural homelessness: A geography without a geography. Journal of Rural Studies, 11(3), 297-307.

Lee, D., Budgell, M., \& Skinner, J. (2007). Happy Valley- 
Goose Bay community plan for addressing homelessness and transitional housing. Retrieved from http://www.nlhhn.org/PDF/HV-GB_Community Plan.pdf

Martin, F. (2013). To go or to stay: Migration decisions and homelessness in East Central Ontario. Retrieved from http://static1.squarespace.com/static/ 521e0ebfe4b0f88e5934ce70/t/52a08c99e4b061dbb 499e0b8/1386253465559/To+Go+Or+To+Stay+\%28 english\%29.pdf

McDermott, V. (2016, June 7). Groups unsure how many of Fort McMurray's homeless population will return. Fort McMurray Today. Retrieved from http:// www.fortmcmurraytoday.com

McNicol, B., \& Glorioso, R. (2014). Second home leisure landscapes and retirement in the Canadian Rocky Mountain community of Canmore, Alberta. Annals of Leisure Research, 17(1). 27-49.

Meert, H., \& Bourgeois, M. (2005). Between rural and urban slums: A geography of pathways through homelessness. Housing Studies, 20, 107-125.

Nichols, N., \& Doberstein, C. (2016). Exploring effective systems respoonses to homelessness. Toronto: Homeless HUB Press.

Nunavut Housing Corporation. (2013). The GN long-term comprehensive housing and homelessness strategy. Retrieved from http://homelesshub.ca/resource/ gn-long-term-comprehensive-nunavut-housing-andhomelessness-strategy

Peressini, T., McDonald, L., \& Hulchanski, D. (1995). Estimating homelessness: Towards a Methodology for Counting the Homeless in Canada. Canada Mortgage and Housing Corporation. Retrieved from http:// www.urbancentre.utoronto.ca/pdfs/researchassoci ates/1996_Peressini-McD-JDH_Estimating-Homeless ness.pdf

Peters, E., \& Craig, S. (2014). Aboriginal homelessness in Flin Flon, Manitoba. Retrieved from http:// ion.uwinnipeg.ca/ epeters/Flin\%20Flon\%20Final\%20 Report-2.pdf

Peters, E. J., \& Robillard, V. (2009). 'Everything you want is there': The place of the reserve in First Nations' homeless mobility. Urban Geography, 30(6), 652-680.

Robertson, K., \& White, M. (2007). Mapping homelessness in rural Nova Scotia: A study of community resources. Ottawa, Ontario, Canada: Service Canada.

Robertson, M., Harris, N., Noftsinger, R., \& Fischer, P. (2007, March). Rural homelessness. Paper presented at the Toward Understanding Homelessness: The 2007 National Symposium on Homelessness Research. Washington. Retrieved from https://aspe. hhs.gov/sites/default/files/pdf/120751/report_0.pdf

Roy, S., Hurtubise, R., \& Rozier, M. (2003). Itinérance en Montérégie: Comprendre le phénomène et identifier les besoins. Collectif de recherche en itinérance, Montréal. Retrieved from http://extranet. santemonteregie.qc.ca/depot/document/3028/re sumeMonteregie.pdf

Schiff, R., \& Brunger, F. (2015). Northern housing net- works: Building collaborative efforts to address housing and homelessness in remote Canadian aboriginal communities in the Context of rapid economic change. Journal of Rural and Community Development, 10(1). Retrieved from http://www.jrcd.ca/view article.php?id=1217\&layout=abstract

Schmidt, R., Hrenchuk, C., Bopp, J., \& Poole, N. (2015). Trajectories of women's homelessness in Canada's 3 northern territories. International Journal of Circumpolar Health, 74: 29778. doi: 10.3402/ijch.v74.29778

Smith, N., \& Fuller, S. (2007). Homelessness in rural PEI, 'Research report'. Retrieved from: http:// homelesshub.ca/resource/homelessness-rural-pei

Standing Senate Committee on Agriculture and Forestry. (2008). Beyond freefall: Halting rural poverty. Ottawa: Government of Canada.

Stewart, C., \& Ramage, S. (2011). A pan-Northern Ontario inventory of homelessness problems and practices: Northern Ontario service deliverer's association. Sudbury: Northern Ontario Service Deliverer's Association.

The Globe and Mail. (2016). The Fort McMurray fire: What's happening now, and what you've missed. Retrieved from http://www.theglobeandmail.com/ news/alberta/the-fort-mcmurray-disaster-read-thelatest-weekend/article29930041

United States Government Accountability Office. (2010). Rural homelessness: Better collaboration by HHS and HUD could improve delivery of services in rural areas. Washington, D.C.: United States Government Accountability Office.

United States Interagency Council on Homelessness. (2015). Opening Doors. Federal strategic plan to prevent and end homelessness. Washington, DC. Retrieved from https://www.usich.gov/resources/ uploads/asset_library/USICH_OpeningDoors_Amend ment2015_FINAL.pdf

Waegemakers Schiff, J., \& Turner, A. (2014b). Housing first in rural Canada: Rural homelessness and housing first feasibility across 22 Canadian communities. Retrieved from http://homelesshub.ca/resource/hous ing-first-rural-canada-rural-homelessness-housingfirst-feasibility-across-22-canadian

Waegemakers Schiff, J., Schiff, R., Turner, A., \& Bernard, K. (2015). Rural homelessness in Canada: Directions for planning and research. The Journal of Rural and Community Development, 10(4), 85-106.

Walsh, C. A., Hanley, J., Ives, N., \& Hordyk, S. R. (2015). Exploring the experiences of newcomer women with insecure housing in Montréal Canada. Journal of International Migration and Integration, 17(3), 1-18.

Young, M. G., \& Moses, J. M. (2013). Neoliberalism and homelessness in the Western Canadian Arctic. Canadian Journal of Nonprofit and Social Economy Research, 4(2), 7.

Yukon Anti-Poverty Coalition. (2011). A home for everyone: A housing action plan for Whitehorse. Retrieved from http://www.yapc.ca/assets/files/a-home-foreveryone.pdf 


\section{COGITATIO}

\section{About the Authors}
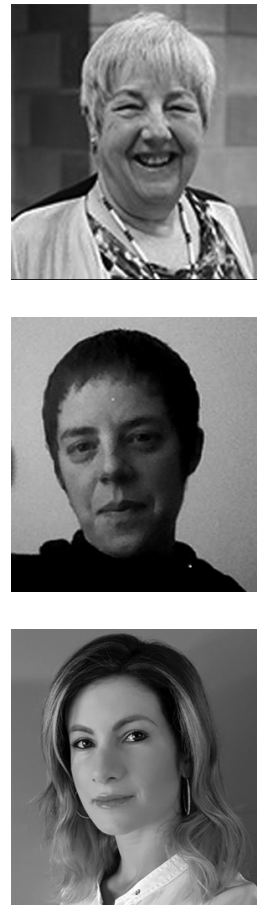

Jeannette Waegemakers Schiff is a faculty member in Social Work at the University of Calgary. Her academic areas span individual practice, program evaluation and administrations, and research in mental health and homelessness. She is a member of the Canadian Homeless Research Network and the organizing steering committee of the Canadian Observatory on Homelessness. She provides program evaluation and consultation to community NGOs and has presented at numerous professional workshops, and conferences.

Rebecca Schiff is a faculty member in the Department of Health Sciences at Lakehead University in Thunder Bay, Ontario, Canada. Dr. Schiff has a long history of working closely with rural, remote, and Indigenous communities across Canada to investigate and research health issues and solutions, with a particular focus on determinants of community health and wellness, social justice, and sustainability.

Alina Turner is recognized as a leading homelessness researcher and is a Fellow at The School of Public Policy, University of Calgary. In her consulting work (Turner Research \& Strategy), she supports with a variety of organizations to support human service system planning and integration. She engages in academic and applied research on issues including housing stress, poverty, domestic violence, migration and rural social issues. 